\title{
Educación interactiva: estrategia pedagógica para resignificar la identidad cultural y comprensión lectora de leyendas Riobambeñas
}

Interactive education: pedagogical strategy to resignify cultural identity and reading understanding of Riobamba legends

Miriam Elizabeth Erazo Rodríguez ${ }^{1}$, Fabián Alfonso Calderón Cruz², Myriam Elizabeth Murillo Naranjo ${ }^{3} \&$ María Belén Ávalos Torres ${ }^{4}$

\begin{abstract}
.
DOI: https://doi.org/10.33262/cienciadigital.v4i4.1421

The development of communication technologies, place education in a transformation process that requires other forms of language, educational processes are exposed to new challenges, demand the use of adequate resources that promote participatory and interactive spaces; This article studies the elements that are part of the legends of the Illustration of Riobamba Legends project as a strategy to strengthen identity in the child population of the Riobamba canton, the objective is to evaluate the use of interactive teaching methodologies from new spaces and learning scenarios. that strengthen the cultural identity of school-age boys and girls. The research methodology is qualitative and quantitative, documentary, ethnographic and content, the information has been contrasted with the results of the application of surveys and observation techniques, which allowed the interpretation and comparison of the data with those obtained in the validated documentary records. for this purpose and to identify the circumstances in which the reading processes take place in the study

\footnotetext{
${ }^{1}$ Universidad Nacional de Chimborazo, Facultad de Ciencias Políticas y Administrativas, Carrera de Comunicación. Riobamba, Ecuador, miriamerazo@unach.edu.ec

${ }^{2}$ Escuela Superior Politécnica de Chimborazo, Facultad de Informática y Electrónica. Carrera de Diseño Gráfico. Riobamba, Ecuador. f_calderon@espoch.edu.ec

${ }^{3}$ Universidad Nacional de Chimborazo. Facultad de Ciencias Políticas y Administrativas. Carrera de Comunicación. Riobamba, Ecuador. myriammurillo@unach.edu.ec

${ }^{4}$ Universidad Nacional de Chimborazo, Facultad de Ciencias Políticas y Administrativas, Carrera de Comunicación. Riobamba, Ecuador. maria.avalos@unach.edu.ec
} 
population. The result of the research shows the importance of the use of interactive methodologies in the teaching-learning processes, and how multimedia resources encourage reading, build dialogic learning processes and are carriers of a sense of relevance in the transmission of legends.

Keywords: Interactive education; pedagogical strategies; reading comprehension; dialogic learning, communication and identity.

\section{Resumen.}

El desarrollo de las tecnologías de la comunicación, sitúan a la educación en un proceso de transformación que requiere otras formas de lenguaje, los procesos educativos están expuestos a nuevos retos, demandan el uso de recursos que propicien espacios participativos e interactivos; este artículo estudia elementos que integran las leyendas del proyecto Ilustración de Leyendas Riobambeñas, como estrategia para el fortalecimiento de la identidad en la población infantil de Riobamba. El objetivo es evaluar el uso de metodologías de enseñanza interactiva desde nuevos espacios y escenarios de aprendizaje, que fortalezcan la identidad cultural entre los niños en edad escolar. La metodología de la investigación es cualicuantitativa, documental, etnográfica y de contenido; la información ha sido contrastada con los resultados de la aplicación de encuestas y técnicas de observación, que permitieron interpretar y comparar los datos con los obtenidos en las fichas documentales validadas para este efecto e identificar las circunstancias en que suceden los procesos de lectura en la población estudiada. El resultado muestra la importancia del uso de metodologías interactivas en los procesos de enseñanzaaprendizaje y cómo los recursos multimedia animan a la lectura, construyen procesos de aprendizaje dialógico y son portadores de sentido de pertinencia en la transmisión de las leyendas.

Palabras claves: Educación interactiva; estrategias pedagógicas; comprensión lectora; aprendizaje dialógico, comunicación e identidad.

\section{Introducción.}

El objetivo de este artículo es evaluar el uso de metodologías de enseñanza interactiva desde nuevos espacios y escenarios de aprendizaje, a partir del uso de herramientas pedagógicas, que contribuyan a la comprensión de textos narrativos, específicamente de las leyendas consideradas en el proyecto Ilustración de Leyendas Riobambeñas como estrategia para el fortalecimiento de la identidad en la población infantil del cantón Riobamba, se pretende mostrar, como a partir de este recurso se fortalece en los estudiantes capacidades y habilidades de interacción, así como la consolidación de procesos cognitivos que permitan repensar los significados que tienen los relatos en las leyendas. 
De aquí que, afianzar la identidad en las niñas y niños en edad escolar, mediante la ejecución de estrategias planificadas como alternativas pedagógicas; promoverán la lectura desde prácticas con base en sus intereses y necesidades, desarrollando en los infantes habilidades lectoras de comprensión, reflexión y crítica que les permitirá desplegar estas competencias en un mundo donde la tecnología cobra fuerza, también en los procesos sociales.

La modernidad en este mundo complejo, implica transformaciones vertiginosas que traen consigo tendencias de cambio en lo ambiental, cultural, económico, y también en los nuevos sistemas de comunicación, que hacen uso de un lenguaje digital universal, e integran globalmente la producción y distribución de palabras, sonidos e imágenes de nuestra cultura y las acomoda a los gustos de las identidades y temperamentos de los individuos. Las redes informáticas interactivas crecen exponencialmente, creando nuevas formas y canales de comunicación, dando forma a la vida a la vez que esta les da forma a ellas (Castells 1999:56).

Los contenidos escolares dejan de ser procesos cerrados donde la forma tradicional de aprender se presenta multimodal, es así que: "A partir de referentes procedentes de investigadores y activistas de la cibercultura, se han abierto paso nuevos conceptos y propuestas que evidencian la necesidad de replantear las prácticas educativas desde una nueva lógica de comunicación" (Amador-Baquiro 2018:4)

Sin duda, la relación entre los medios tecnológicos, la comunicación y la educación es trascendente, cuando es utilizada como estrategia pedagógica, para facilitar y mejorar los procesos educativos, estos términos acuñados desde lógicas dialógicas, e insertas en criterios metodológicos de investigación-acción, deben propender a la búsqueda de nuevas formas de leer, considerando a la educación como un proceso que no es lineal, ni es homogéneo y tampoco escolarizado, sino que es un proceso dialógico, de transformaciones sociales. De esta manera "se hace cada vez más necesario hablar de alfabetizaciones múltiples y formas diversas de leer y escribir el mundo" (Huergo 2017:12)

Resulta claro que el sistema educativo nacional ha ligado a la educación con la escolarización, situación que ha ocasionado complicaciones pedagógicas, de las que derivan prácticas educativas caducas que privilegian la cognición instrumental por sobre una racionalidad comunicativa; estos errores pedagógicos han traído consigo consecuencias negativas sobre todo en los procesos de lectura, porque se desarrollaron de manera sucesiva, lineal, secuencial, siguiendo incluso el nivel por edades y etapas; devaluando así las culturas orales primarias (diálogo, expresiones corporales, etc.) y, más adelante de las culturas orales secundarias (escritura y elementos audiovisuales, virtuales), que a su vez desplazaron la oralidad primaria (Huergo 2017:5).

En todo caso, las transformaciones en el mundo complejo que habitamos tienen consecuencias importantes que se instauran en la tecnología y esta, "la tecnología solo puede potenciar las actividades humanas, no debe sustituirlas y servir para controlarlas. Las 
tecnologías son nuevos caminos, nuevos canales, nuevas formas de hacer. (MachinMastromatteo 2016:38).

Reflexionar acerca de la comunicación ligada indiscutiblemente a la educación, es un proceso necesario que permite este diálogo, sin el cual no hay comunicación y sin esta no hay verdadera educación. Educación que, superando la contradicción educador-educando, se instaura como situación gnoseológica en que los sujetos inciden su acto cognoscente sobre el objeto cognoscible que los mediatiza. (Freire 2019:75), que pretende un lenguaje que debe ser problematizado y desnaturalizado para poder hacer una experiencia autónoma.

Desde esta perspectiva es preciso considerar el uso de los medios tecnológicos como estrategias pedagógicas donde los educadores educandos estén dispuestos a aprender de y con los estudiantes, rompiendo las prácticas educativas tradicionales e incluirse en un proceso creativo y productivo, donde "el educador es un sujeto de conocimiento enfrentado con otros sujetos de conocimiento" (Freire 1990:75).

El docente tiene la importante tarea de observar y verificar que el proceso de enseñanzaaprendizaje sea significativo, de crear canales de comunicación dirigidos al desarrollo tecnológico usando los medios digitales que además son una competencia imprescindible en los educadores, es así que:

La UNESCO (2016) plantea a las competencias digitales para el docente desde la dimensión pedagógica como aquellas habilidades de planificación y organización de elementos que permitan la construcción de escenarios educativos apoyados en TIC para el aprendizaje significativo y la formación integral del estudiante, además deben de poner en marcha el diseño y planificación de un escenario educativo, y que se ven reflejadas en las prácticas educativas de un docente, al igual deben de valorar la efectividad para favorecer el aprendizaje significativo en los estudiantes al incorporar las TIC a sus prácticas educativas (Castillo, et.al 2017:5)

La educación interactiva, es por tanto un recurso importante, a partir del cual el docente puede crear situaciones dialógicas, creando espacios creativos-participativos y reflexivos encaminados al desarrollo del pensamiento crítico. Las escuelas son escenarios sociales donde se construye el aprendizaje, es por esto, que las experiencias compartidas en contextos habituales priorizan autonomía, interaprendizaje, competencias comunicativas, aprendizajes colaborativos y significativos que conviertan al estudiante en el constructor de su propio conocimiento.

Es evidente que el uso de tecnologías ha transformado el proceso de enseñanza- aprendizaje, y se muestra como un recurso eficaz para apoyar la labor docente de forma interactiva. Su influencia en el universo escolar se torna fundamental para intervenir en las dificultades que presentan los estudiantes a la hora de interpretar un texto con sentido (Henao \& Fonseca 
2017:4). De hecho, las niñas y niños tienen contacto con los medios tecnológicos desde edades tempranas, pero su uso no ha sido abordado desde un enfoque netamente educativo.

Esta investigación pretende, por tanto, evaluar la pertinencia de una educación interactiva, con base en las nuevas tecnologías que acerquen tanto al educador como al educando a interactuar en procesos de enseñanza- aprendizaje que resignifiquen la lectura y rescaten las tradiciones orales por medio de las leyendas.

Pero como se ha mencionado anteriormente, nuestro sistema educativo tiene falencias, y una de las consecuencias es el bajo nivel de comprensión lectora de textos, aunado a esto la falta de motivación por la lectura que tiene la población infantil, porque el leer en la escuela se limita solo a la decodificación de signos gráficos, y no contempla otras formas de lectura que conjuguen aspectos lúdicos, como lo son el color, la textura, las imágenes con el texto, es decir, una forma de leer que desarrolle entornos creativos para el aprendizaje, que animen a la lectura y aumenten las experiencias de narración de las niñas y niños.

Entonces, las nuevas tendencias de educación interactiva, según Paredes (2005) no solo radica en la diversión, sino que precisa la posibilidad de pasar de la estructura de las narraciones establecidas por el autor, a que el lector interactúe con los personajes, innove, los haga actuar dentro de la historia a partir de las instrucciones que lee, reflexione e invente desde su quehacer cognoscitivo, el objetivo es romper con lo establecido, que sea él quien tome el control narrativo de la experiencia lectora. Así la autoría estará en manos de las niñas y niños; y la imaginación surgirá como función de instrumento cultural. (p.266)

Sin duda el leer y escribir "son procesos dinámicos complejos que no son reversibles el uno hacia el otro, aunque si son actividades solidarias. El alumno que escribe tiene que implicarse constantemente en actividades de lectura" (Paredes 2005:256). Además, la lectura es una tarea, que implica que el estudiante no solo esté en capacidad de leer temas sencillos, sino de ampliar conceptos de todos los subprocesos y habilidades requeridas para la lectura, mostrando la importancia de una dimensión como la cultural e ideológica que influye en este proceso (Mejía, Del Cristo \& Rodríguez 2011).

De hecho, el leer implica elaborar conclusiones que relacionen y conecten experiencias y conocimientos personales, comprendan el significado de los matices del lenguaje, que lo evalúen críticamente, y lo lean desde su mundo, es decir que lo comprendan, es tener la capacidad de entender, utilizar, reflexionar, interactuar con textos escritos para alcanzar sus objetivos, desarrollar sus conocimientos y potencial, y participar en la sociedad, pero, además, hay que considerar que:

El medio por el cual accedemos a la información textual cambia permanentemente, de lo impreso a las pantallas de computadora o a los smartphones. La estructura y los formatos de los textos han cambiado. Esto a su vez requiere que los lectores desarrollen nuevas estrategias cognitivas y objetivos más claros en la lectura intencional. Por eso, el éxito en 
la competencia lectora no debería estar definido solo por la capacidad de leer y comprender un solo texto. (Ministerio de Educación 2018:7)

La primera infancia es una etapa importante para que la lectura se vuelva un hábito, es preciso entonces re pensar la formación integral de los estudiantes, y en este sentido comprender a la lectura como una función que es fundamental en este proceso; aprender a aprender a través de ella, permite que el desarrollo cognitivo y meta cognitivo, coadyuve al desempeño académico y a la transformación de la sociedad, reafirme y modifique los valores personales y sociales, y relacione las experiencias entre ideas de diversas fuentes (López \& Arciniegas 2004:5).

Pero también durante la lectura surge un acto comunicativo entre el que lee y el texto, por eso es importante elegir el texto adecuadamente ya que la interacción entre ambos explorará significados, y la comprensión se irá construyendo no precisamente al final del texto, sino en el proceso donde el lector es quien decidirá cómo leerlo.

Las leyendas son sin duda un recurso didáctico que responde a las necesidades educativas, son un apoyo metodológico que permitirá trabajar de mejor manera las lecturas para la difusión de tradiciones orales de los pueblos, son un elemento motivador para desarrollar el gusto por la lectura, además tiene un carácter interdisciplinar; se puede utilizar tanto en clases de lengua y literatura, como en clases de historia, antropología, geografía, etc., crea además vínculos de afectividad, que contribuyen a la satisfacción personal de los receptores.

Desde el punto de vista psicológico, es interesante el aprendizaje significativo que además contribuye a formar personalidades equilibradas (Magán 2016:11)

\section{Metodologia.}

La metodología utilizada en la investigación que dio origen a este artículo se alinea dentro del paradigma cuali-cuantitativo y etnográfico, que permiten observar y analizar la presencia y el valor educativo que se confiere a la identidad cultural desde la comprensión de textos en diferentes ámbitos interactivos, el enfoque cualitativo recopila información bibliográfica especializada como PISA y la UNESCO, se ratifica la información contrastándola con las fichas documentales validadas, se ha utilizado la observación participante como estrategia fundamental para la recogida de datos, también el uso de otras técnicas como encuestas, análisis de documentos, $\mathrm{o}$ análisis de contenido.

Los datos obtenidos pretenden revisar la incidencia que tiene la educación interactiva en el proceso formativo mediado por las nuevas tecnologías y qué reflexión o sentimiento les producen a los niños las lecturas sobre las leyendas de Riobamba, para esto se tomó en cuenta el perfil psicográfico de la población en estudio, se obtuvo una muestra de 500 estudiantes con un rango de edad de 10 a 12 años. 
Para iniciar con el proceso metodológico, se identificaron los recursos narrativos e ilustrativos que contienen los textos que se presentan a los niños, el estudio bibliográfico y de contenido, y ratificar la pertinencia con la metodología citada. Además, este artículo permite una reflexión teórica del objeto de investigación, a partir del reconocimiento del contexto de la población en estudio.

También se realizaron entrevistas semiestructuradas a través de un focus group dirigida a ocho expertos, mediante este instrumento se recopilaron 80 leyendas y con base en el artículo Salvaguarda de las leyendas del cantón Riobamba como patrimonio intangible (Idrobo, Pomaquero, Calderón, \& Hidrobo 2018), se ha realizado el inventario de las leyendas del cantón Riobamba, datos iniciales para construir las ilustraciones, narraciones y los escenarios interactivos de los personajes y leyendas (Tabla 1)

Tabla 1. Ficha trabajada con el documento Salvaguarda de las leyendas del cantón Riobamba como patrimonio intangible

\begin{tabular}{|c|c|c|c|c|c|c|}
\hline TIPO DE FUENTE & LIBRO & TÍTULO & \multicolumn{2}{|c|}{ Cuentos ecuatorianos de aparecidos } & $\mathrm{N}^{\circ} \mathrm{ARCH}$ & \\
\hline AUTOR (ES) & \multicolumn{4}{|l|}{ Mario Conde } & AÑO & 2006 \\
\hline CIUDAD & Quito - ECU & EDITORIAL & Grupo Editorial Norma & \begin{tabular}{|l|l} 
Volumen & Vol. I \\
\end{tabular} & $\mathrm{N}^{\circ}$ PAGS & 128 \\
\hline \multirow[t]{2}{*}{ BILIOTECA } & PÚBLICA & \multicolumn{3}{|c|}{ Colegio Maldonado Centro } & & \\
\hline & PRIVADA & & & & & \\
\hline CÓDIGO ARCHIVO & ISBN & $\mathrm{N}^{\circ}$ EJEMPLARES & CONSULTA: $\mathrm{d} / \mathrm{m} / \mathrm{a}$ & & & \\
\hline EC863/C7451C & $9978-54-187-X$ & 1 & $13 / 5 / 2016$ & & & \\
\hline
\end{tabular}

Fuente: Idrobo, Pomaquero, Calderón, \& Hidrobo, 2018

Por otra parte, la observación completó los hallazgos más significativos identificados al interior de las aulas de clase. La información recopilada de las fichas documentales elaboradas según del modelo de análisis de interfaz para productos hipermedia, Mora (2009), en su libro: La interfaz hipermedia: el paradigma de la comunicación interactiva, que fue adaptado para los fines adecuados al proyecto, se aprovechó para localizar contextos y personajes que intervienen en las leyendas; además de su incursión y presencia con el fin de adaptar las leyendas a un lenguaje claro, en armonía con situaciones didácticas dialógicas y significativas (Tabla 2).

Tabla 2. Modelo de análisis de la interfaz para productos hipermedia: aplicación de las descripciones delos elementos expresivos, los niveles de interactividad y las formas narrativas para las leyendas de Riobamba.

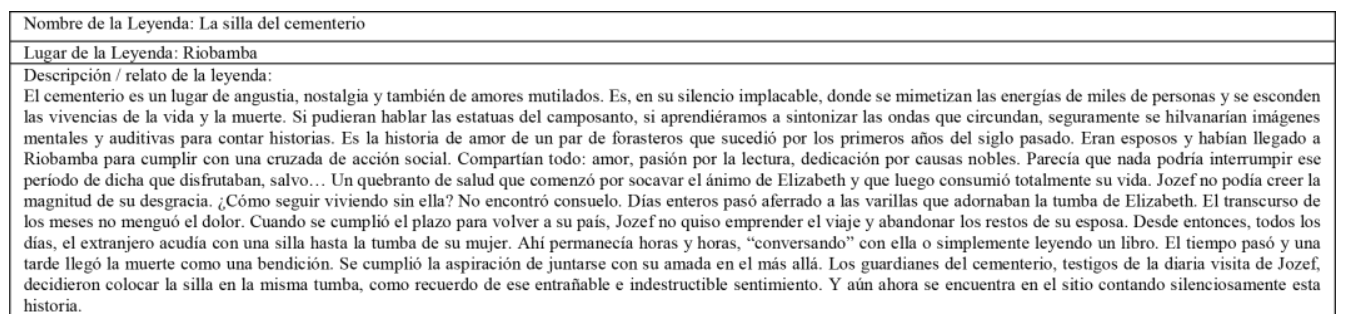




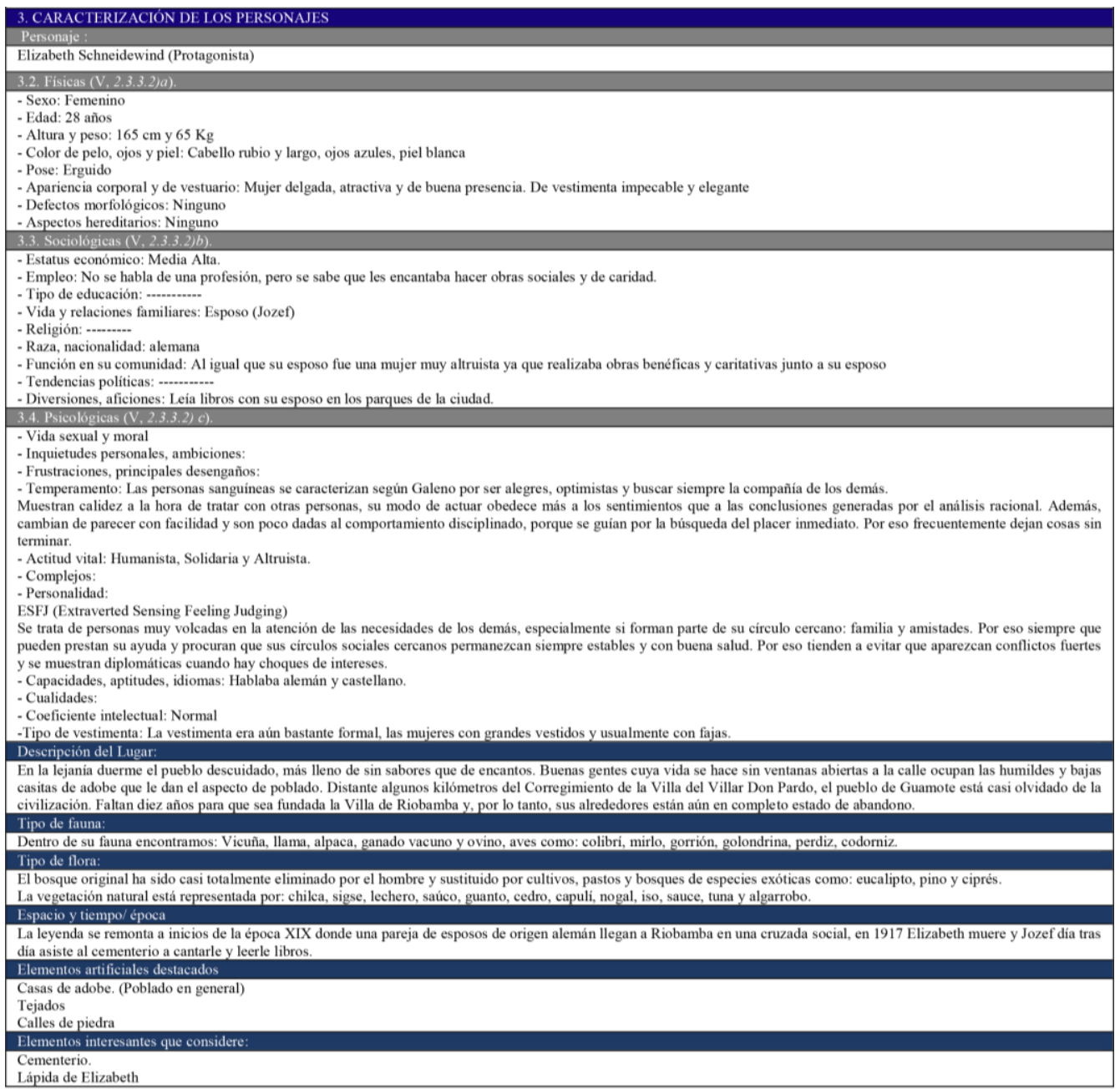

Fuente: Mora, J. (2009). La interfaz hipermedia: el paradigma de la comunicación interactiva. Modelos para implementar la inmersión juvenil en multimedia interactivos culturales. (Videojuegos, cine, realidad aumentada, museos y web).

Se realizó un análisis documental que sustenta a la investigación en la parte teórica de la propuesta, el mismo que se enfoca en explorar la literatura específica que aborda el tema objeto de estudio, a partir de la definición y síntesis de la información de teorías actuales.

\section{Resultados y discusión.}

La educación es uno de los factores determinantes para la transformación social, por eso, su accionar debe consolidarse en la formación integral del individuo, porque es a través de la educación como se mejorarán las condiciones de vida de los seres humanos y el desarrollo de los pueblos tanto en los aspectos culturales, como sociales, económicos y políticos. 
Ahora bien, es evidente la relación inseparable que existe entre la comunicación y la educación, por tanto, es importante el carácter comunicativo que tiene la relación pedagógica, que no solo debe ser tomada como una simple acción instrumental (Habermas, 1976).

Evidentemente la conexión esencial entre educación y comunicación genera posibilidades de mejora en el proceso educativo, porque las dificultades que surgen en él, sin duda son el resultado de la ruptura de la comunicación en la escuela.

Por otro lado, la tecnología de los medios de comunicación ha transformado el modo de concebir y acceder a la información (Aparici \& Davis 1992), los sistemas educativos actualmente incorporan estas formas de comunicación e información dentro de los procesos de enseñanza-aprendizaje; el desarrollo tecnológico ha impactado todos los ámbitos de la vida humana, entre ellos el de la educación, "desde hace algunos años, la informática y tecnología han generado grandes cambios y al mismo tiempo revolucionaron la forma de percibir el mundo globalizado en el ámbito educativo" (Huertas \& Sánchez 2015:42).

Referirse a la comunicación digital interactiva y articularla con los procesos educativos, replanteará de alguna manera las prácticas educativas, de ahí que:

Teniendo en cuenta la diversidad de escenarios en los que ocurre la educación, especialmente en espacios como la escuela, se requiere repensar los procesos educativos, específicamente los currículos, las prácticas pedagógicas y la evaluación del aprendizaje, en torno a dos aspectos claves que surgen de este panorama: otros estilos comunicativos que deberían ser considerados para orientar las prácticas pedagógicas; y tipos de textualidades (alfabéticas, visuales, sonoras, audiovisuales, digitales) que podrían favorecer la construcción y expansión de contenidos escolares más flexibles y abiertos para el desarrollo de determinados aprendizajes en los estudiantes. (Amador-Baquiro 2018:5)

Los procesos de comunicación, ligados sin duda a la educación, emplean lógicas con importantes cargas visuales, que median en los entornos de aprendizaje y las nuevas formas de leer, por eso los procesos de enseñanza - aprendizaje, requieren de la elaboración de estrategias, en las que las prácticas metodológicas propendan a establecer mecanismos de construcción y apropiación del conocimiento, desde contextos de aprendizaje colaborativos y dialógicos donde se aprenda a aprender significativamente, la lectura encuentre nuevos espacios y contextos.

En este sentido, la relación estudiante - profesor y materiales educativos es fundamental, y claramente muestran esquemas de interacciones cognitivas que demandan compartir significados, porque como lo dice (Freire, 2004), la enseñanza no debe ser monológica, sino dialógica, y las nuevas tecnologías hacen posible relaciones de interactividad que favorece el desarrollo de pensamiento analítico, crítico y reflexivo, en que la práctica real del docente, plantee nuevas formas de enseñanza, que sean buscar más allá de las potencialidades interactivas de las nuevas tecnologías, y faciliten el aprendizaje significativo que propicie 
en estudiante experiencias afectivas positivas, pensamientos, sentimientos y acciones que estén integrados en el estudiante como persona (Moreira, 2017).

Los resultados obtenidos de las entrevistas realizadas al focus group, las encuestas, la bibliografía revisada, las fichas documentales y la teoría tienen una relación evidente, estos instrumentos confrontan los esquemas previos e identifican los intereses del grupo en estudio.

Desde esta visión este artículo consideró importante analizar la información recogida en la investigación, y luego de aplicar los instrumentos diagnósticos en instituciones públicas y privadas, tanto a nivel rural como urbano del cantón Riobamba, donde se determinó que los textos oficiales dentro del Ministerio de Educación contemplan en sus contenidos el análisis y el desarrollo creativo de leyendas, sin embargo, el material que existe no cumple con las expectativas de la población investigada; el $17.64 \%$ tiene ilustraciones, pero solo un $11 \%$ es atractiva para las niñas y niños en las edades de estudio; las ilustraciones son monocromáticas y en lo referente a términos linguiísticos no hay claridad en las narraciones de leyendas, cuento y tradición.

Además, en los datos obtenidos de las encuestas del perfil psicográfico aplicadas a la población en estudio, encontramos el perfil conductual, comportamental y discursivo, y los intereses particulares de la población objetiva, el 59\% prefiere leer leyendas y cuentos, los elementos que les atrae de una historia tienen que ver con la interactividad y la lógica visual,

Entonces, las leyendas constituyen una estrategia comunicativa, que:

Participa de características y personajes del mito, del cuento, del romance, de la fábula, etc. Es, en parte, histórica, pero también es explicativa de algunos accidentes y lugares geográficos; en ella tienen cabida los problemas y las preocupaciones del hombre de todos los tiempos: la vida, la enfermedad, la muerte, la comunicación con el más allá, la presencia de seres reales y extraterrenales con poder para ocasionar el bien y el mal, el valor de la religión en la vida del hombre de todas las épocas y la importancia de esta como base de creación de relatos, en los que se narran milagros de santos, vírgenes y cristos que todo lo pueden solucionar en la vida.(Magán 2016:1)

Sin embargo, los avances tecnológicos aparentemente han ido opacando esta práctica. La tecnología ha desplazado las experiencias sociales de trasmisión oral de padres a hijos. La inserción del internet, la televisión satelital, entre otros avances tecnológicos, han provocado una aculturación o una "metamorfosis cultural", por tanto, las identidades locales se siguen debilitando aún más con el paso del tiempo.

Por lo tanto, "necesitamos reconocer un nuevo sensorium en el que los niños y jóvenes que llegan a los espacios e instituciones educativas se mueven en diferentes planos, desde diversas formas sensibles, gustos, modas, deseos, códigos y manifestaciones estéticas" (Huergo 2007:10). El proyecto planteado busca retomar esta práctica, debido a que la 
transformación de la narrativa tradicional, ha adaptado nuevas experiencias no solo instrumentales, comunicativas y técnicas, sino también que:

El regreso a los sentidos, y las operaciones retóricas descritas a través del hipertexto y la convergencia multisensorial, permiten construir discursos hipermediales complejos devolviendo la intencionalidad a los usos de estos recursos y no como parte de un esquema instrumental y desprovisto de significado de uso (Rodríguez 2017:76).

Indudablemente los compendios estéticos, narrativos, emocionales y de valores integrados que refiere (Mora, 2012) son elementos hipermedia con componentes fundamentales a tomar en cuenta durante la creación de productos multimedia interactivos - educativos.

El proyecto Ilustración de Leyendas Riobambeñas como estrategia para el fortalecimiento de la identidad en la población infantil del cantón Riobamba, propone la aplicación del modelo de análisis de interfaces hipermedia, como se muestra en la Tabla 3, ya que a partir de este se pueden manejar el diseño y producción de proyectos educativos interactivos, que exploran la comunicación interactiva narrativa, y nos va a permitir observar cuáles son las relaciones entre las expresiones, cada forma narrativa: acción, personaje, espacio y tiempo, los tipos de interacción, y los valores éticos y no éticos comunicados a través de la interfaz hipermedia.

Las células vacías y las subcategorías, son categorías que servirán para describir las cualidades de las distintas características, y están listas para ser rellenadas y/o seleccionadas durante el análisis descriptivo de las interfaces.

Tabla 3. Modelo de análisis de interfaces hipermedia para observar y registrar contenidos estéticos, elementos narrativos, tipos de interacción y valores éticos y no éticos.

\begin{tabular}{|c|c|}
\hline $\begin{array}{l}\text { 1. Nombre y descripción de las interfaces y el conjunto de expresiones } \\
\text { hipermedias } \\
\text { 1.1. Denominación identificable de la interfaz hipermedia. (Ca - da } \\
\text { interfaz distinta que aparece en el producto hipermedia debe ser } \\
\text { numerado, nombrado y observado bajo este modelo descriptivo para } \\
\text { obtener un análisis profundo). } \\
\text { 2. Características generales de la interfaz y descripción detallada de } \\
\text { las características multimedia de las expresiones de interacción con } \\
\text { cualquiera de los elementos narrativos } \\
\text { 2.1. Software: Grupo de expresiones y herramientas tecnológicas que } \\
\text { sirven para la relación y generación de interacciones naturales y } \\
\text { virtuales. } \\
\text { A) De intermediación icónica } \\
\text { B) Simbólica } \\
\text { A\&B) Combinación de ambas } \\
\text { C) Mimético } \\
\text {-natural } \\
\text { - Abierta o de realidad virtual } \\
\text { - Semiabierta o simuladores de realidad virtual } \\
\text { D) Convergente } \\
\text { E) Interfaces de pull o push } \\
\text { F) Interfaz estática o dinámica } \\
\text { G) Interfaces con sonido o silencio }\end{array}$ & $\begin{array}{l}\text { - Pose } \\
\text { - Apariencia corporal y costumbres } \\
\text { - Defectos morfológicos } \\
\text { - Aspectos hereditarios } \\
\text { 3.3. Características sociológicas } \\
\text { - Status económico } \\
\text { - Empleo } \\
\text { - Tipo de educación } \\
\text { - Vida y relaciones familiares } \\
\text { - Religión - Raza, nacionalidad } \\
\text { - Función en su comunidad } \\
\text { - Tendencias políticas } \\
\text { 3.4. Características psicológicas } \\
\text { - Vida moral y sexual } \\
\text { - Ambiciones personales y motivaciones } \\
\text { - Frustraciones, conflictos principales } \\
\text { - Temperamento: enfadado, tolerante, pesimista, optimista... } \\
\text { - Actitud vital: complaciente, combativo, rendición } \\
\text { - Inseguridades: obsesiones, inhibiciones, supersticiones } \\
\text { - Extrovertido, introvertido, equilibrado } \\
\text { - Capacidades, actitudes, idiomas } \\
\text { - Cualidades: imaginación, criterio, gusto, equilibrio } \\
\text { - Coeficiente intelectual: alto. medio. baio }\end{array}$ \\
\hline
\end{tabular}


H) Interfaces inteligentes

I) De iteración

2.2.Tipo de imágenes o representación perceptual A) Imagen fija

A.1) Foto-mimética

A.2) Foto-infografia

A.3) Info-gráfica

B) Imagen fija con imagen sonora

C) Imagen en movimiento

C.1) Cine-mimética

C.2) Cine-infografia

C.3) Cine-mimética e infografia

D) Imagen visual en movimiento con o sin imagen sonora

E) Imagen audiovisual

F) Imagen sonora

G) Imagen sonora con o sin imagen visual o imagen extraterritorial

2.3. Hardware: Grupo de expresiones fisicas.

A) De intermediación

B) Natural miméticas

2.4. Descripción tipográfica

- Tamaño de letra

- Estilo de fuente o tipo

- Características o efectos de la letra

- Color de la letra

2.5. Descripción icónica

2.6. Descripción simbólica

3. Características de los personajes representados en la interfaz y descripción general de las interacciones potenciales con los personajes

3.1. Personaje o avatar de primera, segunda o tercera persona

3.2. Características físicas

- Sexo

- Edad

- Altura y Peso

- Pelo, ojos y color de piel

9.4. 2D/3D o espacio 4D

9.5. Perspectiva: tamaño, escala, posición y punto de vista

9.6. Enfocado o desenfocado

9.7. Iluminación y temperatura de color

9.8. Atrezzo

9.9. Espacio protagonista $y / o$ hiperespacio

9.10. Espacio ausente o espacio sugerido

9.11. Espacio de selección y que tiene representación: coincidente o diferente

9.12. Hiperespacio

10. Aspectos de los espacios interactivos y tipo de interacción disponible: selectiva, transformativa o constructiva.

11. Valores no éticos o principios espirituales que están disponible para activarse a través de la interacción con las características narrativas del espacio. Valores éticos y no éticos que aparecen potencialmente relacionados con la interacción. 11.1. Valores éticos

11.2. Valores no éticos
4. Aspectos interactuables del personaje y tipo de interacción disponible: selectivo, transformativo o constructivo

5. Valores no éticos o principios espirituales que están disponibles para activarse a través de la interacción con las características narrativas del personaje. Valores éticos y no éticos que aparecen potencialmente relacionados con la interacción.

5.1. Valores éticos

5.2. Valores no éticos

6. Características de las acciones representadas en la interafaz y descripción de las interacciones potenciales con las acciones

6.1. Trama o tema principal

- Relaciones entre las acciones principales y las secundarias

- Relaciones reales entre las acciones principales

-Relaciones reales entre las acciones secundarias

- Relaciones simuladas entre las principales y las secundarias

- Anuladas entre las acciones principales y las secundarias

6.2. Trama o tema secundario

6.3. Tipo de estructura

6.4. Jerarquía cambiante

7. Aspectos de las acciones interactivas y tipo de interacción disponible: selectiva, transformativa o constructiva.

8. Valores no éticos o principios espirituales que están disponibles para activarse a través de la interacción con las características narrativas de las acciones. Valores éticos y no éticos que aparecen potencialmente relacionados con la interacción.

8.1. Valores éticos

8.2. Valores no éticos

9. Características de los espacios representados en la interfaz y descripción de las interacciones potenciales con los espacios

9.1. Natural, construido, mimético-natural o mimético-infográfico

9.2. Sentidos implicados en la percepción espacial: vista, oído, olfato, gusto $\mathrm{y} / \mathrm{o}$ tacto

9.3. Espacio implícito y/o explícito

12. Características de los tiempos representados en la interfaz y descripción general de las interacciones potenciales con los tiempos

12.1. Orden: flashback, flashforward, metaretrospectiva or metaprospectiva

12.2. Duración: diégesis pura, diégesis impura, abierta o cerrada

12.3. Frecuencia: secuencia repetitiva o singular múltiple

12.4. Localización temporal: pasado, presente, futuro, cambiante o inexistente

12.5. Iteración

13. Aspectos de los tiempos interactivos y tipo de interacción disponible: selectiva, transformativa o constructiva.

14. Valores no éticos o principios espirituales que están disponible para activarse a través de la interacción con las características narrativas de los tiempos. Valores éticos y no éticos que aparecen potencialmente relacionados con la interacción

14.1. Valores éticos

14.2. Valores no éticos

Fuente: Mora, J. (2012). Medios interactivos y cultura digital: Alfabetización hipermedia en Perú y Bolivia. Comunicar, 20(39), 139-149.

\section{La interacción texto-imagen en la silla del cementerio.}

Una vez realizado el análisis del Modelo de la interfaz para productos hipermedia: aplicación de las descripciones de los elementos expresivos, los niveles de interactividad y las formas narrativas para las leyendas de Riobamba propuesto por (Mora, 2012). La portada de la leyenda: La silla del cementerio (figura 1), considera en su construcción narrativa la adaptación de la aplicación del modelo mencionado y busca integrar al lenguaje con otros recursos que pueden ser usados como elementos interactivos: la imagen, el texto escrito, la música, la lengua oral, e imágenes en movimiento. 
Figura 1: Portada de la leyenda La silla del cementerio, texto Guardianes de la memoria.

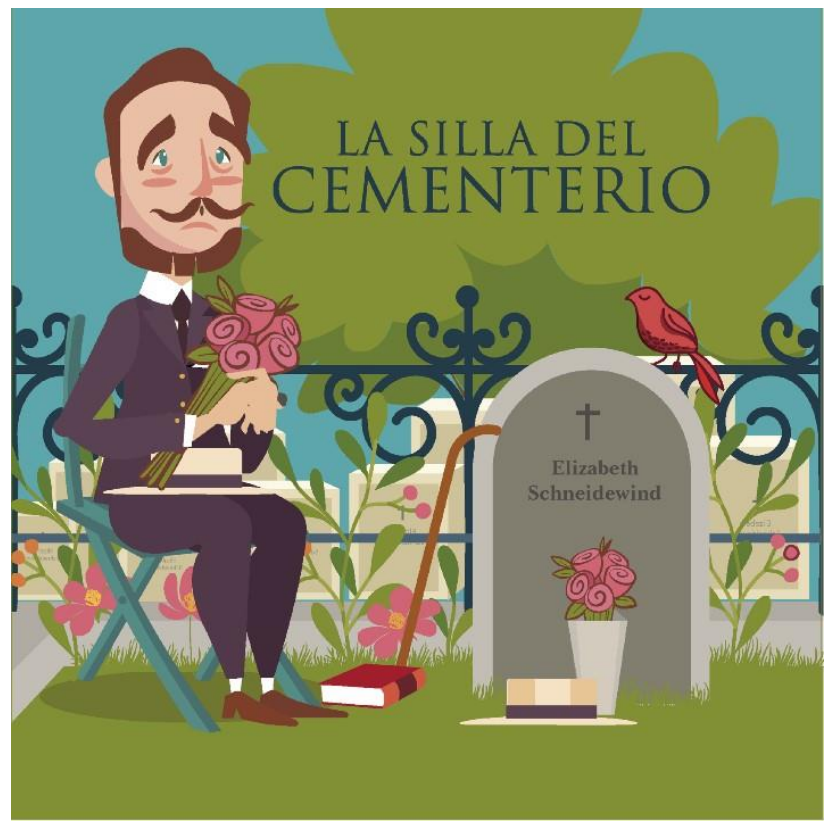

Fuente: Ilustración de Rosa Inés Ramos

Ahora bien, partiremos de la elaboración de narrativas visuales, a partir de la interacción entre el texto y la imagen, para combinarlos dentro de un contexto socio-cultural específico que va a permitir que los significados se adquieran y transmitan de manera interactiva y dinámica.

El significado de las palabras comunica el significado de los elementos visuales, esta complementariedad logra estadios de aprendizaje lector con procesos cognoscitivos superiores, de ahí que:

La descripción verbal también ayuda a mejorar la capacidad de observación visual al mismo tiempo que disciplina la visión al reunir la búsqueda verbal con la visual y ayuda a valorar lo que se observa, crea nuevas interpretaciones subjetivas de la realidad, de las ideas o de los objetos. (Barros \& Barros 2015:30)

La relación entre el texto y la imagen:

Se da por el reconocimiento de las características esenciales de estos públicos lectores a los que es fácil llegar por la identificación de objetos, personajes o circunstancias que conocen o que les impactan, otros por su edad o circunstancias no saben ni siquiera leer y otros más se identifican o idealizan lo que ven. (Lona Olvera 2015:70) 
La primera ilustración (figura 1), refiere los escenarios, los personajes, la relación con los símbolos, de esta manera el ilustrador:

Prolonga el sentido del relato, que tiene como finalidad conducir a los lectores a la fantasía a través de elemento visuales novedosos y diferentes. Dicha ilustración normalmente acompaña a un texto, donde ambos se complementan, aportando conexión, coherencia y contenido a la obra literaria. Se pueden señalar varias funciones:

1. Crea la atmósfera de la obra. Los colores, así como la técnica que el ilustrador utiliza, nos indican el ambiente en que se sitúa la historia. Aporta información al lector sobre el entorno, los personajes, etc.

2. Otorga el tono. Las ilustraciones nos sugieren el contenido humorístico, poético, irónico, del cuento.

3. Provoca al espectador sensaciones muy íntimas que incitan a tomar una postura en relación con lo expuesto por el autor.

4. Ofrece la oportunidad de un diálogo. o. El lector observa la imagen y esta, a su vez, penetra en el lector produciéndole sensaciones como risa, miedo, sorpresa, ternura, etc. (Jorge 2018:5)

La segunda ilustración: La muerte de Elizabeth (figura 2) la relación texto -imagen es neutral, porque el texto no tiene más peso que el componente visual y viceversa, es decir que el texto escrito está reflejado visualmente.

Los rostros de los personajes representan la tragedia que describe el texto, además la utilización del color y la luz en el escenario entregan información significativa que enriquece la percepción de la historia.

Figura 2: Ilustración leyenda: La silla del cementerio, texto: Guardianes de la memoria

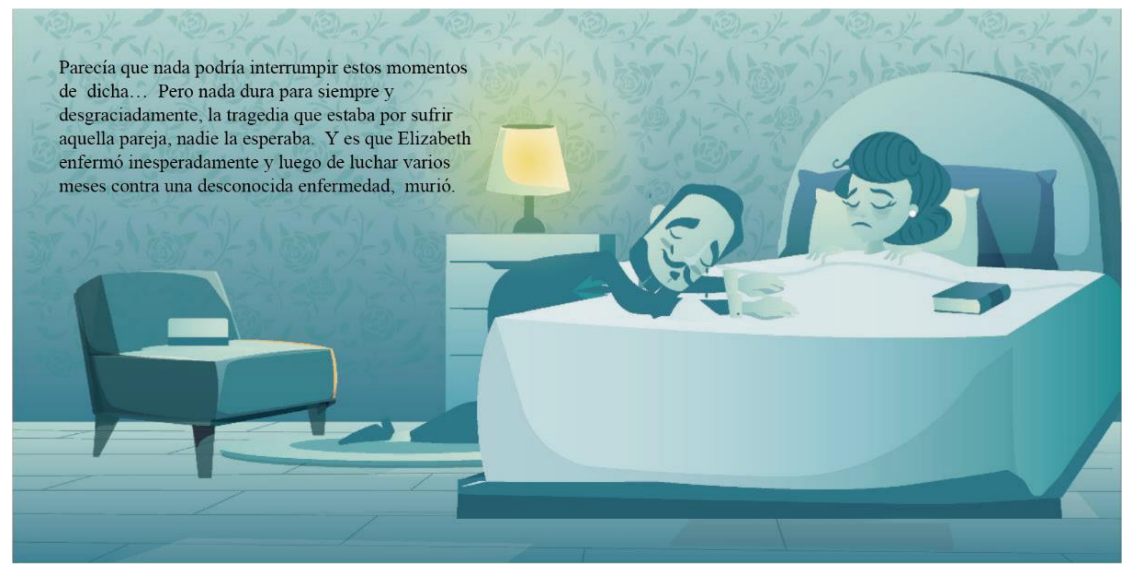


Fuente: Isutración Rosa Inés Ramos

Por otra parte, la integración del lenguaje con otros recursos como ya se ha mencionado, amplía y complementa a partir la relación texto / imagen, otros elementos interactivos que les ofrezca otras posibilidades de leer y comprender los textos, hacer de él un “objeto lúdico, atractivo y manipulable, capaz de ofrecer distintos niveles e itinerarios de lectura que inciten a la participación" (López 2018:5). El siguiente link: https://indd.adobe.com/view/f7d1ee55e13f-406c-9e4d-4e838ae66302 (Diseño interactivo: María José Haro).

El diseño interactivo muestra que es posible materializar una interacción comunicativa expresiva, que parta del nivel de los personajes, tercera ilustración: Jozep y Elizabeth (Figura 3) y las acciones, donde el avatar, el lecto-autor o jugador, materializa la interacción expresiva, la inmersión o la identificación mediadora. Esta es la razón por la que los elementos expresivos que aparecen en la interfaz son descritos como elementos que sirven para la interacción y construcción del personaje o avatar (Mora, 2012)

Figura 3: Ilustración leyenda: La silla del cementerio, texto: Guardianes de la memoria.

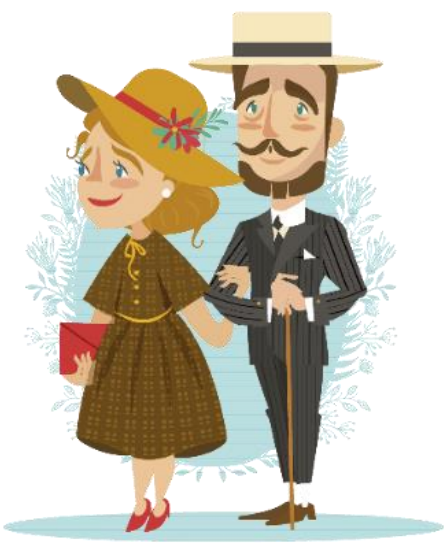

Fuente: Ilustración Rosa Inés Ramos

Dice la historia que, por los primeros años del siglo XIX, el progreso de la ciudad de Riobamba era indiscutible, esta urbe floreciente y con un sinfín de asuntos interesantes en relación con lo cultural, económico, político y social, fue el lugar preferido para un gran número de familias extranjeras.

Esta condición de la ciudad ideal y casi perfecta atrajo a una pareja de esposos extranjeros que llegaron a Riobamba con el fin de cumplir con una cruzada de acción social. Los esposos Schneidewind, Jozep y Elizabeth, de origen alemán, eran una pareja de jóvenes atractivos y de buena presencia, vestían siempre elegantes e impecables, además eran, seres humanos solidarios y altruistas; lo compartían todo, sus gustos y aficiones, amor, pasión por la lectura y sobre todo la dedicación por causas nobles. 
Si bien es cierto, de la escuela tradicional hemos aprendido que la lectura es una actividad que se realiza para obtener información que versa consideraciones específicas sobre diversos temas, es menester ir más allá de este concepto un tanto simplista sobre este proceso cognoscitivo importante, y es que la lectura implica no solo memorizar mecánicamente la descripción de un objeto, sino aprender su significado profundo, vivir intensamente el acto de leer, por lo tanto, es esencial proponer la curiosidad de los alumnos de manera dinámica y viva para que surja la comprensión lectora(Freire, 1991).

Por ello se hace necesario repensar la importancia del acto de leer desde una comprensión crítica de sus lectores: los niños; pero es preciso, que a través de prácticas educativas centradas en el alumno, la educación junto con la comunicación y la información, desarrollen por medio del uso de las TIC'S espacios de aprendizaje interactivos, considerados para un público que no es homogéneo, ni aprende de forma lineal solamente, sino que interacciona activamente en entornos donde la comunicación es esencialmente multimodal y por lo tanto tiene diversas formas de lectura.

Aun cuando las herramientas tecnológicas se han incorporado a los procesos de enseñanza aprendizaje, es necesario que se construyan textos con sentido, donde quienes forman parte del proceso educativo se involucren en la elaboración de nuevas estructuras curriculares que respondan al contexto de los lectores, y estén capacitados en innovaciones pedagógicas desde una mirada dialógica, que resignifque la lectura de leyendas como resultado de productos hipermedia interactivos.

En este sentido la interacción texto-imagen se complementan visualmente; la selección cultural y visión del mundo aplicadas en las leyendas ilustradas multimedia, motivan indudablemente al interés por la lectura, y los niños leen en formatos de lectura heterogéneos, participativos y dialógicos, pensados desde la aplicación de modelos de narrativas transmedia, que como lo dice Galindo (2018) su utilización supone un aporte significativo por contribuir a los procesos creativos, de sensibilidad, imaginación y formación de lo interactivo.

\section{Conclusión.}

- El análisis realizado con base en el Modelo propuesto por (Mora, 2012), muestra como la aplicación de recursos interactivos erigen significados que transmiten aspectos que construyen narrativas desde nuevas estrategias, que no se limitan únicamente al lenguaje, sino que combinan, amplían y complementan los relatos desde nuevas lógicas de aprendizaje dinámico y dialógico.

- El proceso educativo indiscutiblemente debe ser interactivo, los contenidos de aprendizaje están ligados con la comunicación y la información, estos elementos 
generan conexiones significativas, que permiten al lector interactuar con los personajes, los escenarios, los sonidos, desde una narrativa sencilla y comprensiva.

- Utilizar recursos interactivos y combinarlos dentro de un contexto socio-cultural específico en el aprendizaje, va a permitir que los significados se adquieran y transmitan de manera participativa y dinámica. La práctica pedagógica interactiva potencia la comprensión lectora en la población de estudio, porque al ser la comunicación inherentemente multimodal, las narrativas digitales aplicadas en la investigación han consolidado la hibridación del texto - imagen que ha sido la base para el proceso de cuentos interactivos, la producción de hipertextos, que muestran e incorporan juegos, imágenes, audios, actividades y demás recursos hipermedia para que los niños lean desde otros escenarios y nuevos soportes de lectura participativos.

- En cuanto al educador - educando se ha promovido romper con la forma tradicional de enseñar, y la importancia de presentar nuevos escenarios de aprendizaje que respondan a las necesidades de los estudiantes, donde la comunicación y el diálogo fomenten en las niñas y niños espacios interdisciplinarios, que generen lecturas del mundo con elementos textuales que emocionen, se disfruten y se comprendan.

- La educación interactiva sin duda alguna propende a generar espacios, recursos y metodologías donde la comunicación facilita los procesos de enseñanza-aprendizaje y el maestro comparta con sus estudiantes desde una lógica de aprender a aprender desde distintos entornos para lograr aprendizajes significativos, que los lleve a resinificar la identidad cultural y comprensión lectora de leyendas de Riobamba.

\section{Referencias bibliográficas.}

Amador-Baquiro, J. C. (2018). Educación interactiva a través de narrativas transmedia: posibilidades en la escuela. Magis. Revista Internacional de Investigación en Educación, 10(21), 77-94.

Aparici, R., \& Davis, B. (1992). La educación para los medios de comunicación. In Colectivo de autores. European conference about information technology in education: a critical insight. Barcelona, Congreso TIE (p. 546).

Barros, C., \& Barros, R. (2015). Los medios audiovisuales y su influencia en la educación desde alternativas de análisis. Revista Universidad y Sociedad, 7(3), 26-31.

Castells, M. (1999). La era de la información: economía, sociedad y cultura. La sociedad Red. (Vol. 1). México. Siglo XXI. 
Castillo, A. G. R., Peña, H. H. Z., Avalos, P. P., Méndez, M. E., \& Macías, A. G. (2017). Las competencias TIC en Educación. Descripción de las competencias digitales en los alumnos de nuevo ingreso. Revista Electrónica sobre Tecnología, Educación y Sociedad, 4(7).

Freire, P. (1990). La naturaleza política de la educación. Cultura, poder y liberación. Barcelona. Ediciones Paidós Ibérica, S.A

Freire, P. (1991). La importancia de leer. México DF Siglo XXI Editores.

Freire, P. (2004). Pedagogía de la Autonomía. Saberes necesarios para la práctica educativa. São Paulo, Brasil: Paz e Terra, S.A.

Freire, P. (2019). Pedagogía del oprimido. 12 libros para educar de Paulo Freire para educar para la libertad. Campaña Latinoamericana por el Derecho a la Educación. (Pedagogy of the oppressed). México DF, México: Siglo XXI

Habermas, J. (1976). ¿Qué significa pragmática universal? Teoría de la acción comunicativa: $\quad$ complementos y estudios previos, 299-368.

Henao, C. M. T., \& Fonseca, M. N. M. (2017). Las TIC: estrategia para mejorar la competencia lectora-interpretativa en el área de lenguaje. Revista Universidad Católica Luis Amigó, (1), 126-148.

Huertas, D. C. P., \& Sánchez, O. N. (2015). Gestión del conocimiento en educación con tic en la transformación de la escuela. Revista vínculos, 12(1), 41-55.

Idrobo, C., Pomaquero, Y., Calderón, F. A., Nina, H., \& Fernanda, A. (2018). Salvaguarda de las leyendas del cantón Riobamba como patrimonio intangible. Revista Caribeña de Ciencias Sociales, (06), 87.

Jorge, C. (2018). Ilustrando cuentos de Hans Christian Andersen. (Tesis Doctoral),

Facultat de

Belles Arts de Sant Carles, Universidad Politécnica de Valencia.

Huergo, J. (2007). Los medios y tecnologías en educación. La Plata. Consultado el 20 de abril de $2020 . \quad$ Disponible en: http://www.me.gov.ar/curriform/publica/medios_tecnologias_huergo.pdf

Huergo, J. (2017). Nuevos apuntes sobre la pedagogía de la comunicación. Revista Q, 2(3), $1-22$. 
Lona, I. (2015). Narrativas contemporáneas: el libro álbum. Economía Creativa, (3), 65-80. Recuperado a partir López, G. S y Arciniegas E. (2004). Metacognición, lectura y construcción de conocimiento. El papel de los sujetos en el aprendizaje significativo. Cátedra UNESCO. Cali, Colombia: Universidad del Valle.

López, A. V. (2018). Las narrativas digitales en Educación Infantil: una experiencia de investigación e innovación con booktrailer, cuentos interactivos digitales y Realidad Aumentada. Diablotexto Digital, 3, 111-131.

Machin-Mastromatteo, J. D. (2016). Cultura de la información, desarrollo abierto, tecnologías

sociales y participación ciudadana. In Gobierno abierto y ciudadanía digital (pp. 129170). Alfagrama.

Magán, P. M. (2016). Las leyendas y su valor didáctico. Centro Virtual Cervantes, 400, 392403.

Mejía, M., Del Cristo, R. \& Rodríguez, B. P. (2011). Estrategias de comprensión lectora mediadas por tic. Una alternativa para mejorar las capacidades lectoras en secundaria. Escenarios, 9(2), 18-25

Ministerio de Educación de la República de Perú. (2018). Marco de evaluación de la competencia lectora de PISA 2018. Lima, Perú: Oficina de Medición de la Calidad de los Aprendizajes.

Mora, J. (2009). La interfaz hipermedia: el paradigma de la comunicación interactiva. Modelos para implementar la inmersión juvenil en multimedia interactivos culturales. (Videojuegos, cine, realidad aumentada, museos y web). Madrid, España: Sociedad General de Autores y Editores. Fundación autor.

Mora, J. (2012). Medios interactivos y cultura digital: Alfabetización hipermedia en Perú y Bolivia. Comunicar, 20(39), 139-149.

Moreira, M. A. (2012). La teoría del aprendizaje significativo crítico: un referente para organizar la enseñanza contemporánea. Revista iberoamericana de educación matemática, 31, http://ciecpress.centro.edu.mx/ojs/index.php/CentroTI/article/view/266

Galindo, J. J. (2018). Transmedia storytelling para las infancias: una estrategia para promover la literatura infantil colombiana, el caso del cuento infantil El Trágala de 
Panfila del autor José Luis Díaz-Granados (Doctoral dissertation, Corporación Universitaria Minuto de Dios).

Paredes, J. (2005). Animación a la lectura y tic: creando situaciones y espacios. Revista de Educación, núm. extra 1, 255-279.

Rodríguez, F. A. (2017). Lecturas de viaje. Apuntes sobre la narración multimedia en video desde la práctica docente e investigativa en la Facultad de Comunicación de la Universidad de La Habana. Alcance, 6(12), 56-80.

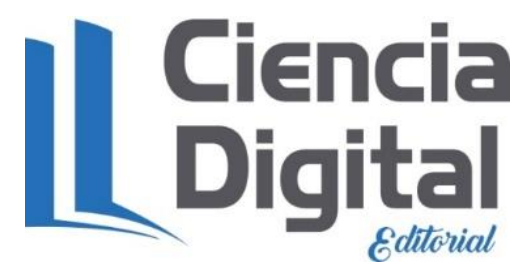




\section{PARA CITAR EL ARTÍCULO INDEXADO.}

Erazo Rodríguez, M. E., Calderón Cruz, F. A., Murillo Naranjo, M. E., \& Ávalos Torres, M. B. (2020). Educación interactiva: estrategia pedagógica para resignificar la identidad cultural y comprensión lectora de leyendas Riobambeñas. Ciencia Digital, 4(4), 44-64. https://doi.org/10.33262/cienciadigital.v4i4.1421

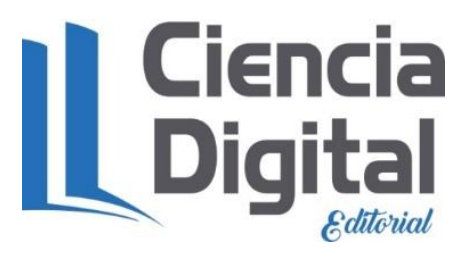

El artículo que se publica es de exclusiva responsabilidad de los autores y no necesariamente reflejan el pensamiento de la Revista Ciencia Digital.

El artículo queda en propiedad de la revista y, por tanto, su publicación parcial y/o total en otro medio tiene que ser autorizado por el director de la Revista Ciencia Digital.
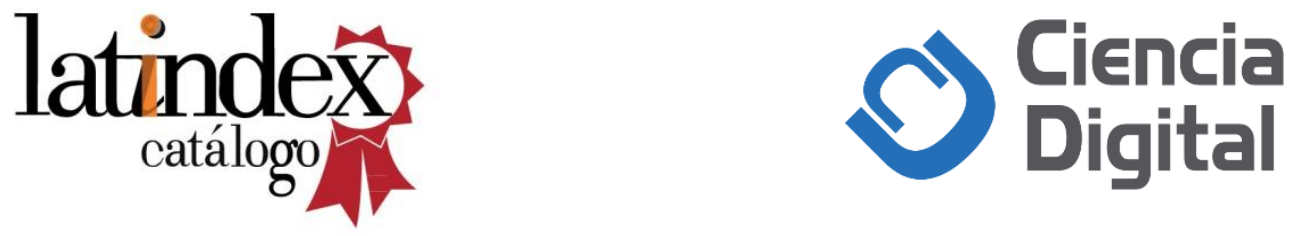